\title{
Regional Seismic Activity after 2012 M8.6 Sumatra Earthquake
}

\author{
Shantha S.N. Gamage ${ }^{1 *}$, D.R.L. Dodangodage ${ }^{1}$, R.M.T.S. Ratnayake ${ }^{l}$ and \\ P. Dias ${ }^{2}$ \\ ${ }^{1}$ Department of Physics, University of Sri Jayewardenepura \\ ${ }^{2}$ Department of Statistics, University of Sri Jayewardenepura
}

Date Received 02-05-2018

Date Accepted: 15-10-2018

\begin{abstract}
The Sumatra subduction zone, one of the most active plate tectonic margins in the world, is characterised by the Indo-Australia Plate subducting beneath the Sunda plate and Andaman micro plate, causing seismic activity along the plate boundary. There had been five major earthquakes of magnitude greater than 8.0 in this region from 2004 to 2014. Three of them are dip-slip and rest of the two is strike-slip type events. Regional earthquake activity after the occurrence of those five events was analyzed.
\end{abstract}

Hypocentral data obtained from the Data Management Center at the Incorporated Research Institutions for Seismology for the period from January 2000 to December 2014 of magnitude 3.0 were used for the analysis. A statistical analysis was carried out to know whether earthquake activity has increased after the major five events and the analysis was carried out both qualitatively and quantitatively. The results of the analysis show that the number of earthquakes in the region has increased considerably after the occurrence of April, 2012 magnitude 8.6 and 8.2 strike-slip events. Further results show that there is no change in the regional earthquake activity after the occurrence of other three major dip-slip type events. Present study results reasonably agree with the results obtained by the other studies carried out with different methods.

In the context of Sri Lanka, strike-slip type focal mechanism of the 2012 two major events may be the reason for increasing of activity in the region, especially in Eastern part of Sri Lanka near Maduruoya, Highland-Wijayan boundary and Wadinagala area of Ampara District.

Keywords: seismology, Sumatra subduction zone, regional seismicity, earthquake, Sri Lanka

\section{Introduction}

Earthquakes are one of the most destructive natural phenomena of the Earth and it is a sudden movement of Earth releasing accumulated energy over a long period of time. The study of earthquakes has been providing a major significance for better understanding of the plate tectonics and the internal structure of the Earth. The tectonic plates move continuously due to the convectional currents of the Lithosphere. The plate velocity is different from plate to plate

${ }^{*}$ Correspondence: shanthagamage@sci.sjp.ac.lk

(C) University of Sri Jayewardenepura 
and is around 0-3cm/year (Read and Watson, 1975) and these motion cause plates to collide with each other. According to the type of collisions there are three types of plate boundaries. In Subduction zones plates collide with each other and one plate subducts under the other, these zones are down going limbs of the mantle convection system, where cold oceanic plates formed at mid ocean ridges return to the deep mantle (Stein and Stein, 1996; Gamage et al., 2009).

Subduction zones are generally characterised by well-defined inclined seismic zones extending, in some cases, down to about 500-670 km deep beneath the Earth. The Sumatra subduction zone is characterised by the Indo-Australia Plate subducting beneath the Sunda plate and Andaman micro plate about $55 \mathrm{~mm} / \mathrm{yr}$, causing seismic activity along the plate boundary (DeMets et al., 2010). Therefore a large number of earthquakes takes place in the region. Large earthquakes are followed by large amount of aftershocks which are smaller in magnitude.

The geometry of faulting during earthquake fault slip is denoted by focal mechanism solutions. Spatial distribution of focal mechanisms will give us information about earthquake generating stresses in and around the focal area. Information on stress distribution in the study region would improve the understanding of seismotectonics in the region. In subduction zones most of the earthquakes are dip slip type where the plates mostly shifted upward or downward. Dip slip type earthquake will release its energy comparably due to its basic geometry. Divergent plate boundaries and plates which move parallel will generally create strike slip type faults are vertical fractures where the plates mostly move horizontally. Strike slip type creates stress on the opposite plate boundary or on a fault of the plate. This stress will be released later creating earthquakes.

In this research the Sumatra subduction zone is the main focus area where large numbers of earthquakes are occurring. The Sunda arc, extending over 5,600 km from the Andaman Islands in the northwest to the Banda arc in the East, was formed by the convergence between the Indo Australian and Eurasian plates. The Sumatra subduction zone lies within the Sunda arc. Generally, tectonic features that affected Sumatra Island can be divided into two seismic source zones which are subduction and transform fault zones. The Sumatra subduction zone is used to classify all of those earthquakes that occurred near convergent boundaries where the Indo-Australian plate is being subducted under the Eurasian plate (Gamage, 2017).

The Sumatra subduction zone is one of the most active plate tectonic margins in the world. Several large earthquakes have occurred in this region in the last two centuries. These events include ones in 1833 with a magnitude of 8.8-9.2, in 1861 with a magnitude of 8.3-8.5, in 2004 with a magnitude of 9.0-9.3 and in 2005 with a magnitude of 8.7. There have been 5 major earthquakes of magnitude greater than 8.0 in this region from 2000 to 2014. Those five were recorded on 26th December 2004, 28th March 2005, 12th September 2007, and two on 11th April 2012. Three of them are dip-slip and rest of the two is strike-slip type events. The magnitude 9.0-9.3 Sumatra-Andaman earthquake of 26 December 2004, was the most severe among the top nine earthquakes reported during the last two centuries. Regional earthquake activity also has increased recently due to unknown reasons.

The recent studies have found that large number of earthquakes have been triggered worldwide after the M8.6 Strike Slip event that occurred in Sumatra region on $11^{\text {th }}$ April 2012 (Pollitze et al., 2012). This intra-oceanic earthquake precipitated a large, abrupt increase in seismicity worldwide and it reached remote distances of 10,000-20,000 km from the main 
shock, much wider than the near-field aftershock zone surrounding a large main shock, which is generally a few fault lengths in size. Johnson, et al., 2015 also showed that the increased seismicity in the elevated strain region within 10 days after the 1977 M8.3 which located in the Indian Ocean in addition to the 2012 M8.6 event. Further, the $2002 \mathrm{M}_{\mathrm{w}}$ 7.9 Denali Fault, the $2004 \mathrm{M}_{\mathrm{w}} 9.2$ Sumatra, the $2011 \mathrm{M}_{\mathrm{w}} 9.1$ Tohoku-Oki and the $2010 \mathrm{M}_{\mathrm{w}} 8.8$ Maule, Chile earthquake have triggered clear tremors in various regions by distant earthquakes (Aiken et al., 2013; Chao et al., 2013; Richards-Dinger et al., 2010).

The main objective of this research is to find out whether there is any change in the regional earthquake activity due to above mentioned five events spicily after the event that occurred in 2012. Therefore seismic activity of, Sumatra region, inland and offshore of Sri Lanka after the occurrence of those five events was analyzed.

\section{Methodology}

By considering the regional seismic activity after the 2004 Sumatra Tsunami earthquake and the earthquake activity of Sri Lanka, the area from $50^{\circ} \mathrm{E}$ to $120^{\circ} \mathrm{E}$ and from $40^{\circ} \mathrm{S}$ to $25^{\circ} \mathrm{N}$ was chosen as the study area. The region was divided into 25 blocks for the process of analysis. Hypocentral data obtained from the Data Management Center at the Incorporated Research Institutions for Seismology for the period from January 2000 to December 2014 of magnitude 3.0 were used for the analysis. Spatial distribution of focal mechanisms was analyzed for major events to investigate the geometry of faulting during earthquake fault slip using the data available from the Global Centroid Moment Tensor solution database for the above period. The Generic Mapping Tools (GMT) was used to create geophysical illustrations. A statistical analysis was carried out to know whether earthquake activity has increased after the major five events. For this purpose, the analysis was done both qualitatively and quantitatively.

Along the plate boundary large number of earthquakes take place and most of them are aftershocks generated by large events. In order to remove the effects of aftershocks and their main events from the analysis, only the data from the blocks with dark borders shown in Fig. 1 were considered.

\subsection{Categorisation}

Fig. 2 shows the magnitudes of the earthquakes occurred during January 2000 to April 2014. The Earthquakes with larger magnitudes are referred as major events in this particular research, earthquakes higher than magnitude 8 are considered as major events and their locations are shown in Fig. 1. Table 1 shows the details about the major earthquakes. Among those major events three are Dip slip types and one is strike slip type. The analysis is carried out relating these four major events. The energy released by the major earthquakes were compared with the cumulative energy of earthquakes occurred before and after each major event. Seismic moment was calculated for this purpose. 


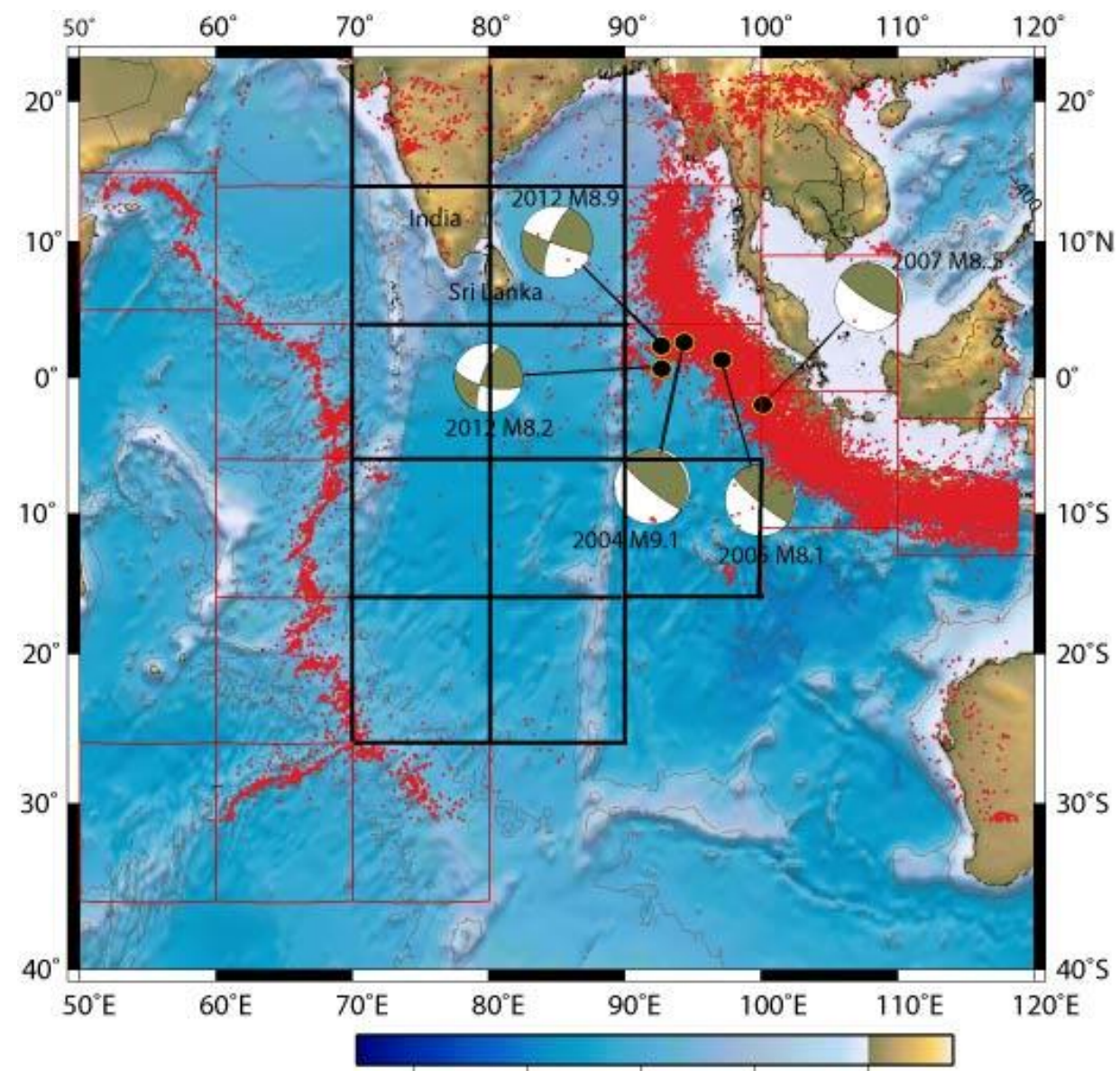

Figure 1: The location of all the earthquakes that occurred from January 2000 to April 2014. Focal mechanisms of the earthquakes greater than M 8.0 are shown in red colors and studied sub regions are shown in squares. Color bar represents bathometry of the region.

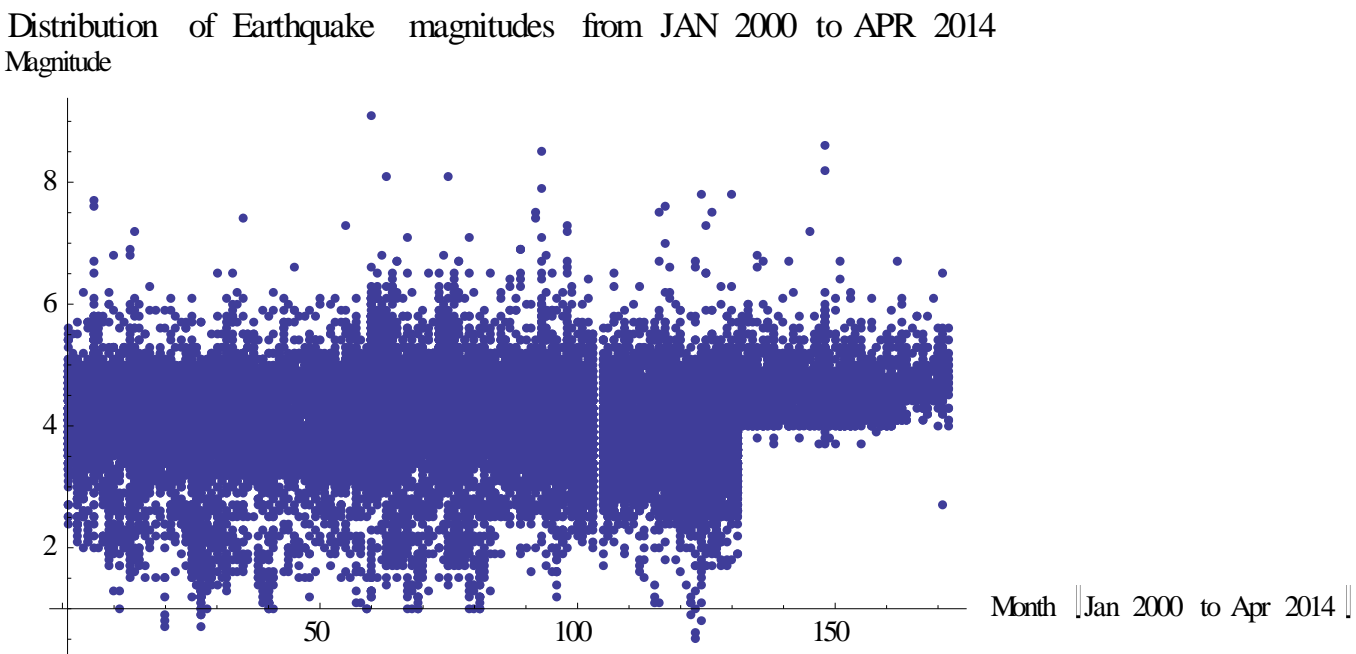

Figure 2: The magnitudes of all the earthquakes from Jan 2000 to Apr 2014. 
Table 1: Description of the major earthquakes.

\begin{tabular}{llllll}
\hline Earthquake & Magnitude & Strike & Dip & Slip & Type \\
\hline $26^{\text {th }}$ December 2004 & 9.1 & 329 & 8 & 110 & Dip Slip \\
$28^{\text {th }}$ March 2005 & 8.1 & 329 & 7 & 109 & Dip Slip \\
$12^{\text {th }}$ September 2007 & 8.5 & 327 & 12 & 114 & Dip Slip \\
$11^{\text {th }}$ April 2012 & 8.6 & 201 & 75 & 6 & Strike Slip \\
\hline
\end{tabular}

\subsection{Method of analysis}

In order to achieve the objective of the research project both quantitative and qualitative analysis were conducted.

The distribution of the number of earthquakes is unknown hence statistical techniques are required which do not need the form of the distribution. Therefore a nonparametric test Mann Whitney U test (Mood, 2010) was done for quantitative analysis. Mann Whitney U test is an efficient test to compare two samples. The sorted data were analysed qualitatively as well as quantitatively to make conclusions of change in number of earthquakes after major events. Minitab 14 was used to do the statistical analysis. The medians of the samples are compared and it is assumed that all the observations from both groups are independent from each other. The number of earthquakes is recorded month wise before and after the major earthquake. The data is listed for 24 months before and after the event. The parameters before and after represent the number of events that happened before the major event and the number of events that happened after the major event. ETA1 and ETA2 are the medians of the "Before" and "After" the sample. The samples were tested to see whether there is any significant difference between the medians. If there is any difference, the sample was retested to see whether median is greater or lesser.

Statement of hypothesis to test whether there is any difference. (Hypothesis A)

$H_{0}: E T A 1=E T A 2 \& H_{1}: E T A 1 \neq E T A 2$

Statement of hypothesis to test which one is greater. (Hypothesis $B$ )

$H_{0}: E T A 1 \geq E T A 2 \& H_{1}: E T A 1<E T A 2$

$p$-value and the Interpretation of the result

The p-value is a probability of rejecting the null hypothesis $\left(\mathrm{H}_{0}\right)$. If the p-value is less than level of significance, the null hypothesis $\left(\mathrm{H}_{0}\right)$ is rejected and the alternate hypothesis $\left(\mathrm{H}_{1}\right)$ is accepted. The level of significance was taken as 0.05 .

\section{Results}

\subsection{Descriptive analysis}

This analysis was conducted by comparing descriptive statistic data which included in Table 2 and comparison of histograms before and after the earthquakes. Fig. 3.1 shows all the events that occurred 24 months before and after the earthquake on 26th December 2004. From Table 2 and Fig. 3.1, it is clear that the average number of events per month has not changed after the earthquake. Fig. 3.2 illustrates the number of events greater than 4 that occurred during 24 months before and after the earthquake. Table 2 shows that the average number of events 
greater than 4 per month has not changed. Therefor it is clear that the number of events has not changed in the region after the 2004 Sumatra event.

According to Fig. 3.3 and the statistics of Table 2, it can be concluded that the number of events per month has not changed after the $28^{\text {th }}$ March 2005 event. The average number of events per month before the event is 7.500 and it is equal to the value after the event. When Fig. 3.4 and statistics of Table 2 are considered the number of events per month has not changed for the earthquakes which are $\mathrm{M}>4$, the average number of events per month before and after the earthquake is 1.00 . Overall the number of events per month has not changed after the earthquake of 28th March 2005.

Fig. 3.5 and the statistics of Table 2 indicate that the number of events per month has decreased after the $12^{\text {th }}$ September 2007 event. The average number of events per month before and after the earthquake is 7.000 and 5.000 respectively. Fig. 3.6 shows the number of events greater than 4 occurred 24 months before and after the 2007 event. According to Fig. 3.6 and the statistics on Table 2 it can be concluded that the number of events of $M>4$ per month has increased. The average number of events per month before the earthquake is 1.000 whereas after is 2.000. It can be concluded that the number of earthquakes of $\mathrm{M}>4$ in the region has increased after the event of 2007.

Fig. 3.7 and data in Table 2 implies that the number of events per month has increased after the 2012 event. The average number of events per month before and after the event is 1.000 and 2.000 respectively. Fig. 3.1 and Table 2 shows that the number of events of $M>4$ per month has increased. Number of events have increased after the earthquake on 11th April 2012. According to the descriptive analysis the number of events has not changed after the events of $24^{\text {th }}$ December 2004 and $28^{\text {th }}$ March 2005. These events are Dip slip type events. Only the number of events of $M>4$ has increased after the event of $12^{\text {th }}$ September 2007 and number of all events has increased after the event on $12^{\text {th }}$ April 2012.

\subsection{Quantitative analysis}

First, the event that occurred 26th December 2004 were considered and Hypothesis A was tested for the earthquake of magnitudes in all the range. The $p$ value $(0.1486)$ is greater than the value of $\alpha=0.05$. Therefore $\mathrm{H}_{0}$ cannot be rejected and there is no significant difference in the medians of the two samples. The number of events in the range between 0 and 10 has not changed after the earthquake of 26th December 2004. For the earthquakes of magnitudes greater than four, $p$ value $(0.0133)<\alpha$. Therefore $\mathrm{H}_{0}$ is rejected. Then hypothesis $\mathrm{B}$ was tested. Tested results show that $\mathrm{p}$ value $(0.0067)<\alpha$ and $\mathrm{H}_{0}$ is rejected. There is a significant difference in the medians of the two samples and the number of events of magnitudes greater than 4 has increased after the occurrence of 26th December 2004 earthquake. Therefore the number of events has not changed after the earthquake but there is an increase in the number of events which are greater than four.

The same method were applied for rest of the events. For the event of 28th March 2005, the $p$ value (0.3979) is greater than the value of $\alpha$. Therefore $\mathrm{H}_{0}$ cannot be rejected and there is no significant difference in the medians of the two samples. For the earthquakes of magnitudes greater than $4, p$ value $(0.3979)>\alpha$. Therefore $\mathrm{H}_{0}$ cannot be rejected, thus there is no significant difference in the medians of the two samples. The number of events of $M>4$ has not changed after the occurrence of earthquake of 28th March 2005. 


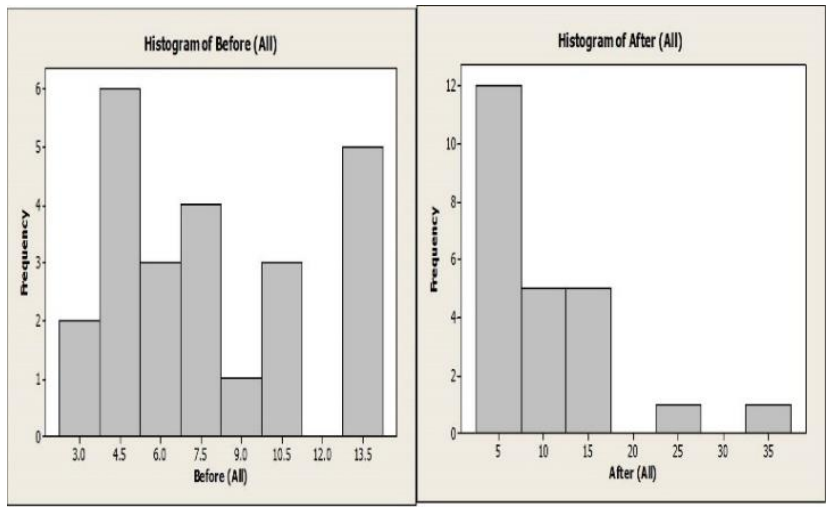

Figure 3.1 Histogram showing the number of earthquakes per month (In all magnitude range) for a period of two 24 months

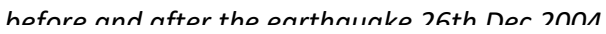

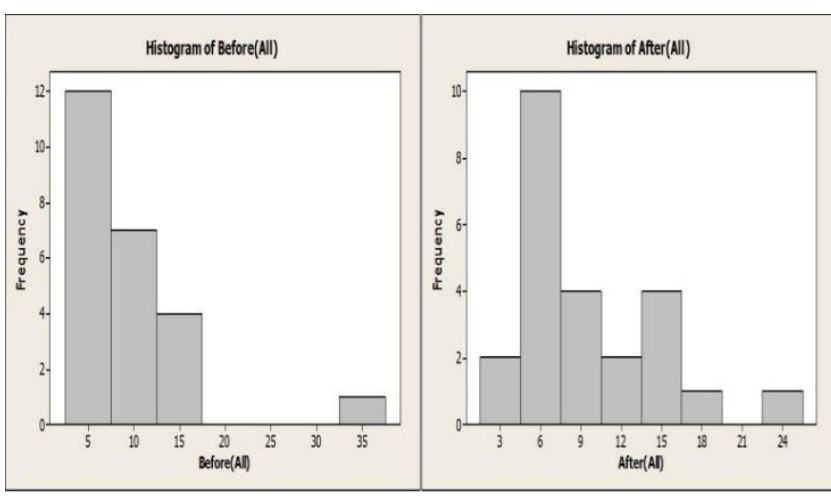

Figure 3.3: Histogram showing the number of earthquakes per month (In all magnitude range) for a period of two 24 months before and after the earthquake 28th Mar 2005.
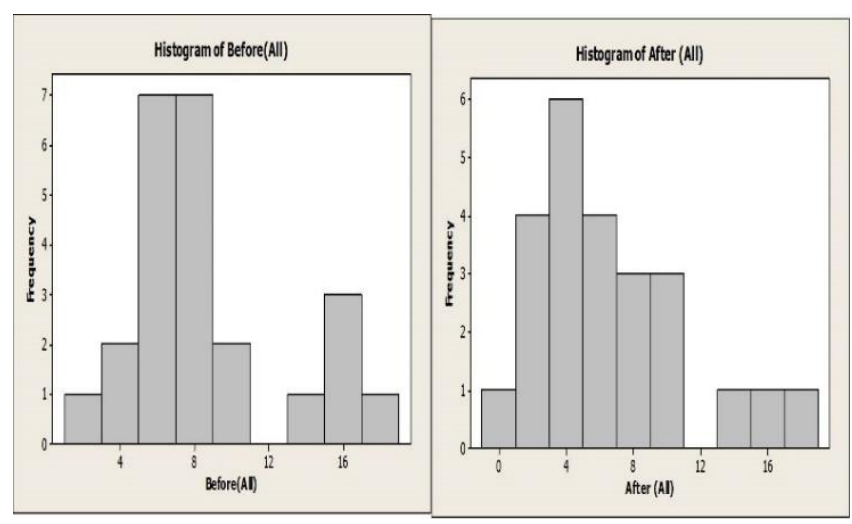

Figure 3.5: Histogram showing the number of earthquakes per month (In all magnitude range) for a period of two 24 months before and after the earthquake 12th Sep 2007

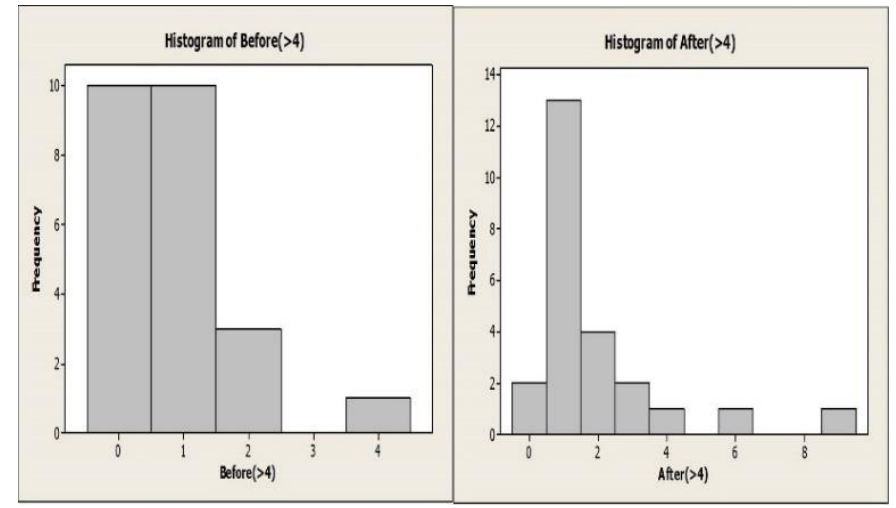

Figure 3.2: Histogram showing the number of earthquakes per month (magnitude greater than 4) for a period of two 24 months before and after the earthquake 26th Dec 2004
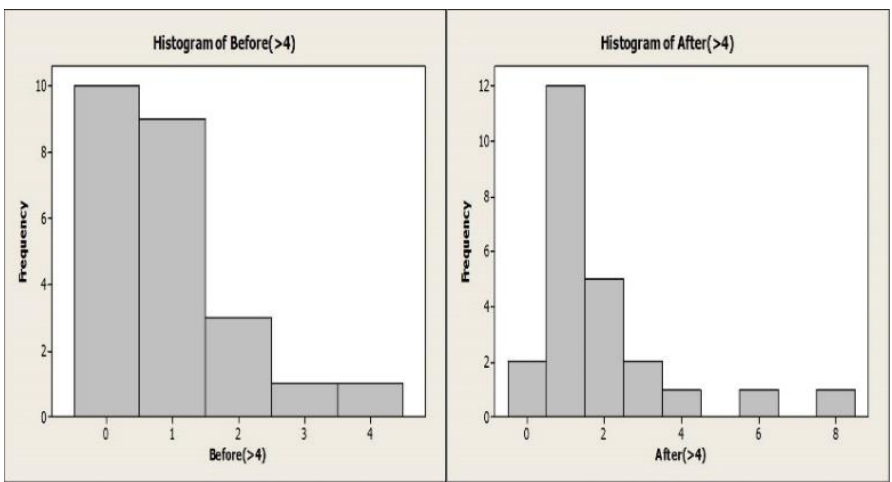

Figure 3.4: Histogram showing the number of earthquakes per month (magnitude greater than 4) for a period of two 24 months before and after the earthauake 28th Mar 2005.

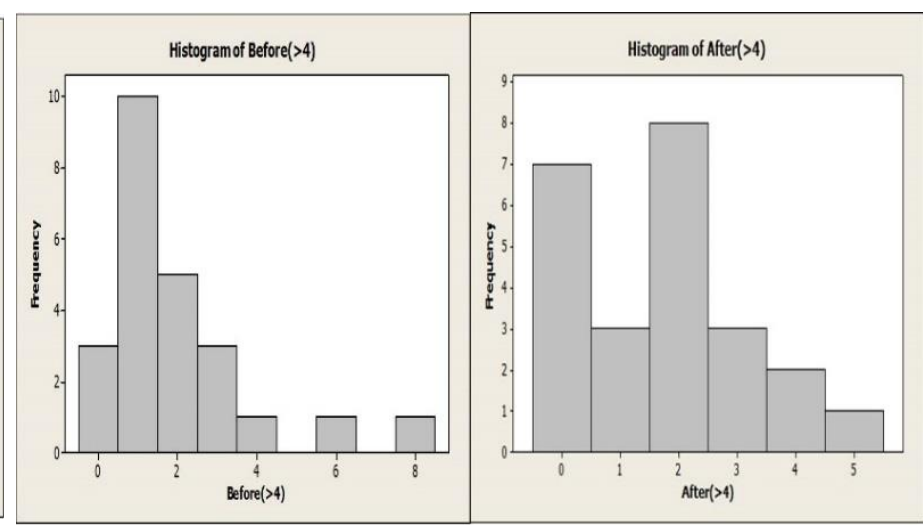

Figure 3.6: Histogram showing the number of earthquakes per month (magnitude greater than 4) for a period of two 24 months before and after the earthquake 12th Sep 2007 

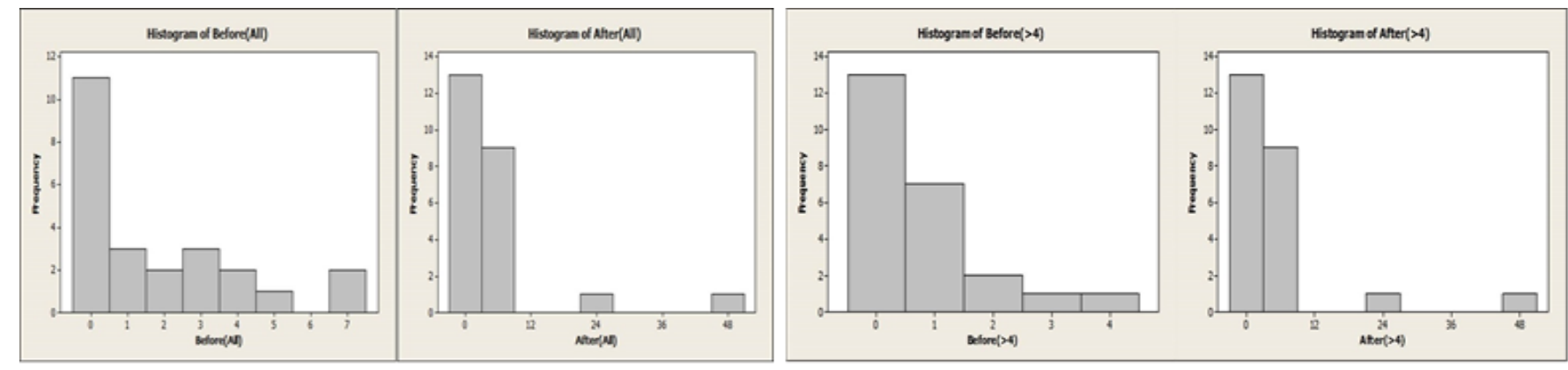

Figure 3.7: Histogram showing the number of earthquakes (In all magnitude Figure 3.8: Histogram showing the number of earthquakes (magnitude greate

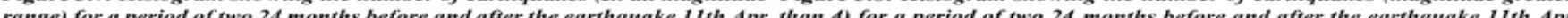
$\begin{aligned} & \text { range) for a period of two } 24 \text { months before and after the earthquake 11th Apr than } \\
& 2012\end{aligned} \mid$\begin{tabular}{c}
2012 \\
\hline
\end{tabular}

Table 2: Descriptive statistics of earthquakes.

\begin{tabular}{|c|c|c|c|c|c|c|c|c|c|c|}
\hline Year & Variable & $\begin{array}{l}\text { Total } \\
\text { count }\end{array}$ & Mean & St dev & Min & Q1 & Median & Q3 & Max & Skews \\
\hline \multirow[t]{4}{*}{2004} & $\begin{array}{l}\text { Before } \\
\text { (All) }\end{array}$ & 24 & 7.985 & 3.689 & 3.00 & 5.00 & 7.500 & 10.00 & 14.00 & 0.51 \\
\hline & $\begin{array}{l}\text { After } \\
\text { (All) }\end{array}$ & 24 & 10.63 & 6.95 & 3.00 & 6.00 & 7.500 & 14.50 & 34.00 & 2.03 \\
\hline & $\begin{array}{l}\text { Before } \\
(>4)\end{array}$ & 24 & 0.833 & 0.963 & 0.00 & 0.00 & 1.00 & 1.00 & 4.00 & 1.63 \\
\hline & $\begin{array}{l}\text { After } \\
(>4)\end{array}$ & 24 & 1.917 & 1.998 & 0.00 & 1.00 & 1.00 & 2.00 & 9.00 & 2.44 \\
\hline \multirow[t]{4}{*}{2005} & $\begin{array}{l}\text { Before } \\
\text { (All) }\end{array}$ & 24 & 9.00 & 6.26 & 3.00 & 5.25 & 7.50 & 10.00 & 34.00 & 2.96 \\
\hline & $\begin{array}{l}\text { After } \\
\text { (All) }\end{array}$ & 24 & 9.63 & 5.20 & 2.00 & 6.00 & 7.50 & 14.50 & 24.00 & 1.01 \\
\hline & $\begin{array}{l}\text { Before } \\
(>4)\end{array}$ & 24 & 0.917 & 1.060 & 0.00 & 0.00 & 1.000 & 1.000 & 4.000 & 1.37 \\
\hline & $\begin{array}{l}\text { After } \\
(>4)\end{array}$ & 24 & 1.917 & 1.840 & 0.00 & 1.00 & 1.000 & 2.000 & 8.000 & 2.14 \\
\hline \multirow[t]{4}{*}{2007} & $\begin{array}{l}\text { Before } \\
\text { (All) }\end{array}$ & 24 & 8.125 & 4.132 & 2.000 & 6.00 & 7.000 & 9.000 & 17.000 & 0.92 \\
\hline & $\begin{array}{l}\text { After } \\
\text { (All) }\end{array}$ & 24 & 6.167 & 4.556 & 0.000 & 3.00 & 5.000 & 9.500 & 17.000 & 1.00 \\
\hline & $\begin{array}{l}\text { Before } \\
(>4)\end{array}$ & 24 & 1.958 & 1.876 & 0.000 & 1.00 & 1.00 & 2.750 & 8.00 & 1.92 \\
\hline & $\begin{array}{l}\text { After } \\
(>4)\end{array}$ & 24 & 1.708 & 1.459 & 0.000 & 0.00 & 2.00 & 2.750 & 5.00 & 0.46 \\
\hline \multirow[t]{4}{*}{2012} & $\begin{array}{l}\text { Before } \\
\text { (All) }\end{array}$ & 24 & 1.792 & 2.245 & 0.000 & 0.00 & 1.00 & 3.00 & 7.00 & 1.16 \\
\hline & $\begin{array}{l}\text { After } \\
\text { (All) }\end{array}$ & 24 & 5.000 & 10.50 & 0.000 & 0.25 & 2.00 & 4.00 & 49.00 & 3.68 \\
\hline & $\begin{array}{l}\text { Before } \\
(>4)\end{array}$ & 24 & 0.750 & 1.073 & 0.00 & 0.00 & 0.00 & 1.00 & 4.00 & 1.70 \\
\hline & $\begin{array}{l}\text { After } \\
(>4)\end{array}$ & 24 & 4.96 & 10.51 & 0.00 & 0.25 & 1.50 & 4.00 & 49.00 & 3.68 \\
\hline
\end{tabular}


For the event of 12th September 2007, the p value (0.0696) is greater than the value of $\alpha$. There is no significant difference in the medians of the two samples. When Earthquakes of magnitudes greater than 4 are considered $p$ value $(0.9097)>\alpha$ for hypothesis A. Therefore $\mathrm{H}_{0}$ cannot be rejected, consequently there is no significant difference in the medians of the two samples. The number of events (earthquakes of magnitudes greater than 4) has not changed after the earthquake on 12th September 2007. According to the tests the number of earthquakes has not changed significantly after the earthquake 12th September 2007.

For the event of 11th April 2012, the $p$ value (0.1975) $>\alpha$ hence $\mathrm{H}_{0}$ cannot be rejected. Therefore there is no significant difference between the medians of the two samples. $\mathrm{H}_{0}$ cannot be rejected and there is no significant difference in the medians of the two samples. In contrast, when Earthquakes of magnitudes greater than 4 are considered p-value $(0.0086)<\alpha$ thus $\mathrm{H}_{0}$ is rejected and it can be concluded that there is a significant change in the number of earthquakes greater than four. As previous results indicated there is a difference between numbers of earthquakes before and after, hypothesis B is tested. $p$-value $(0.0043)<\alpha$, as a result is rejected. There is a significant change in the number of earthquakes greater than four. The number of earthquakes is greater than the number of events happened 24 months before the earthquake 11th April 2012. As an overall the number of total events has not changed but the earthquakes of magnitude greater than four has increased after the occurrence of 11th April 2012 event.

\subsection{Overall interpretation on the analysis}

The results of the qualitative analysis indicates that the number of events per month has not changed after the events of 26th December 2004 and 28th March 2005. However it has decreased after the event of 12th September 2007 whereas it has increased after the 11th April 2012 event. In contrast, when the number of events greater than magnitude four are concerned, there is no change the number after the events of 26th December 2004 and 28th March 2005 while the number has increased after the events of 12th September 2007 and 11th April 2012. Quantitative analysis confirms the qualitative analysis as the results differ marginally from the qualitative analysis. The number of events has not changed after the events of 26th December 2004, 28th March 2005, 12th September 2007 and 12th April 2012. For the earthquakes of magnitudes greater than 4 , the results are as follows. The number of events has increased after the events on 26th December 2004 and 11th April 2012. The number of events has not changed after the events on 28th March 2005 and 12th September 2007.

\subsection{Analysis of earthquake energy}

The energy released by the major earthquakes were compared with the cumulative energy of earthquakes occurred before and after each major event and it was calculate using the equation (1).

$\log _{10} E=4.4+1.5 M$

Fig. 4 illustrates the energy released by the major earthquakes while Fig. 5 shows the total energy released in each time period before and after the major events. When the data in the graphs are considered it clearly indicates that there is no significant increase of energy released after the events occurred in 2004, 2005, 2007 respectively. In contrast, the energy released aftermath of the 11th 2012 April 8.6 M has been increased. Hence this confirms results of the statistical analysis that the earthquake activity has increased after the 2012 major earthquake of 8.6 magnitude. 


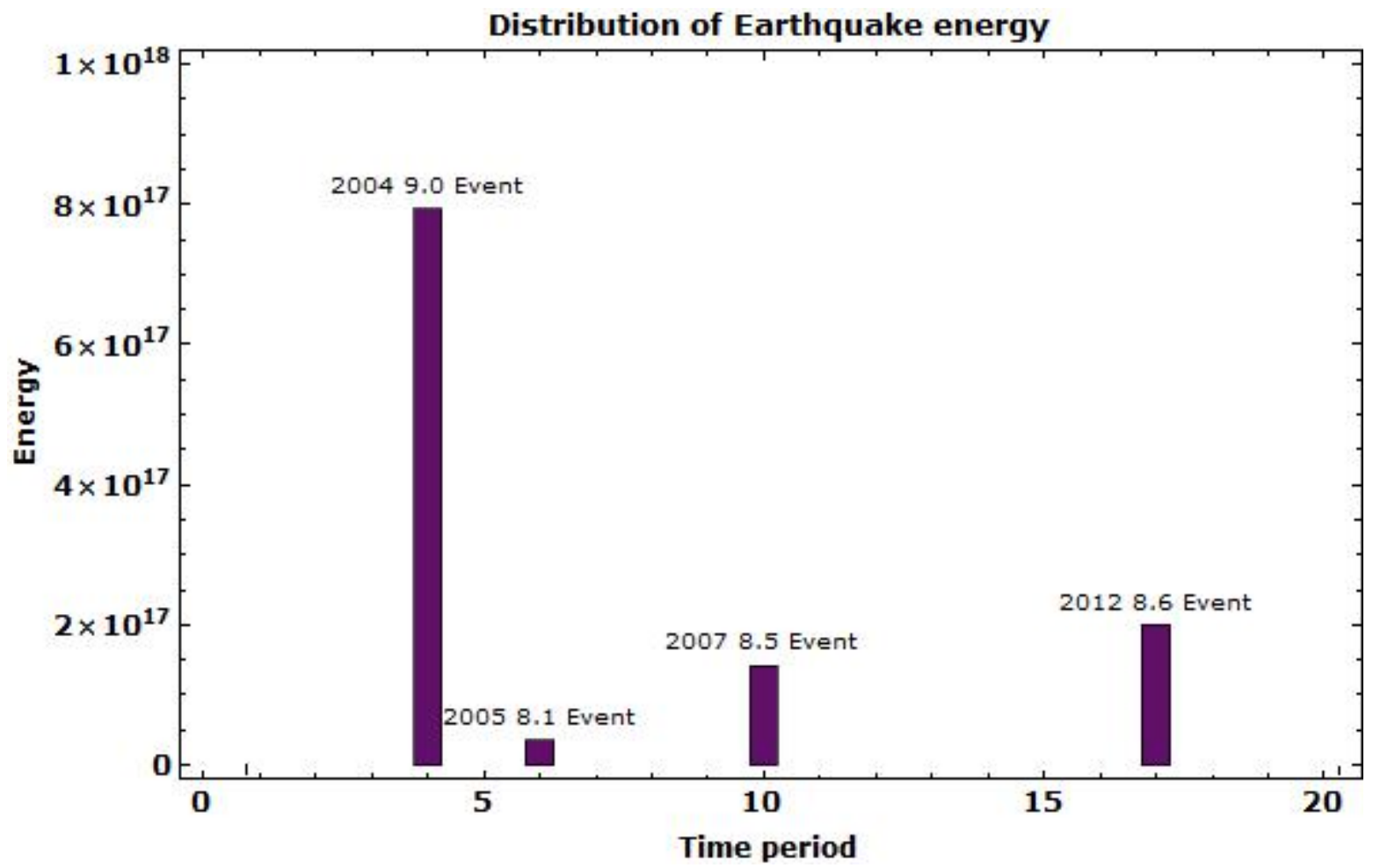

Figure 4. Energy bar chart of major events.

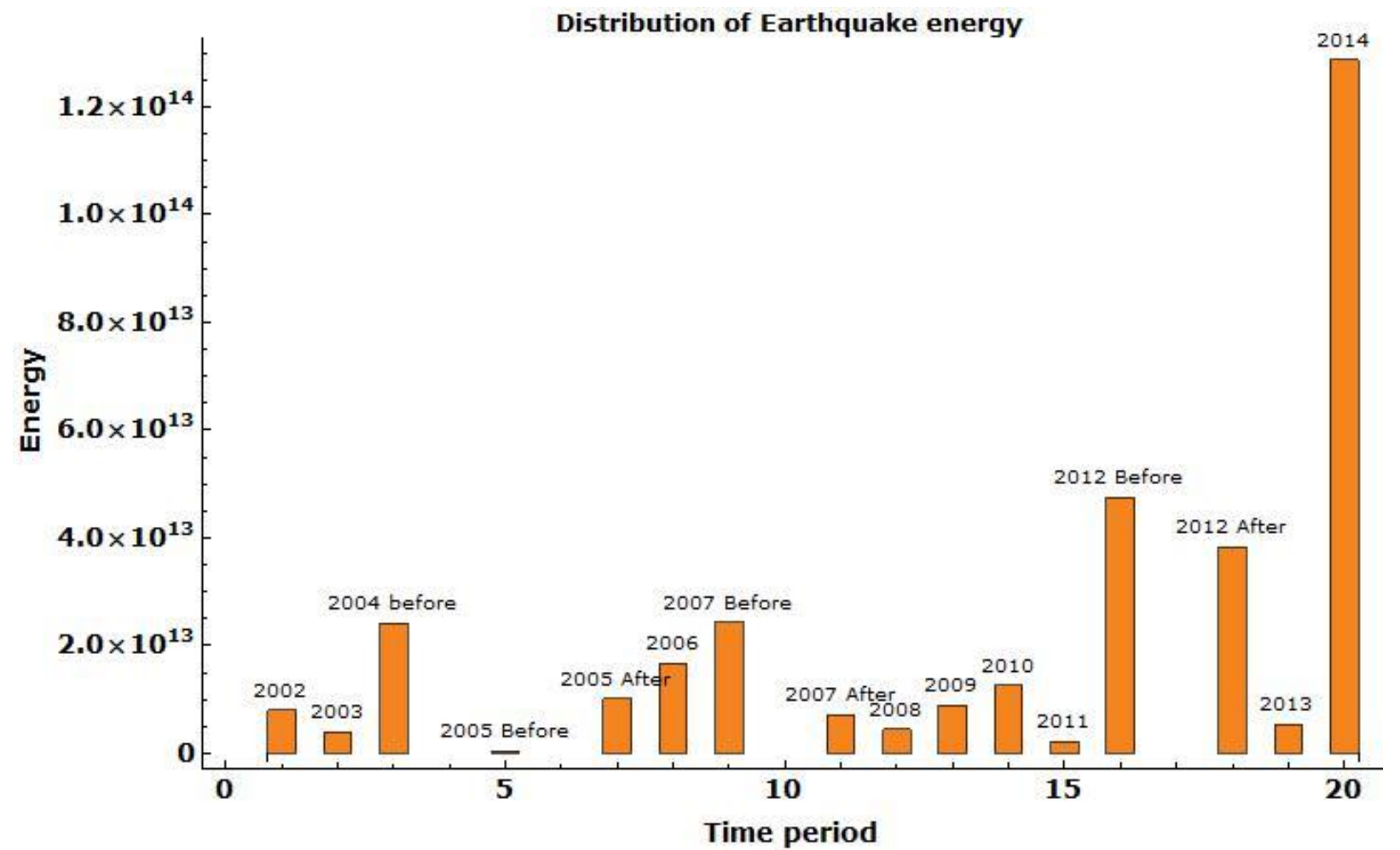

Figure 5. Energy Bar Chart according to the years excluding Major Events. 


\section{Discussion}

The number of earthquakes has not changed after the major earthquakes on 26th December 2004, 28th March 2005, and 12th September 2007. The number of earthquakes of M>4 has increased after the occurrence of earthquake on 11th April 2012. The data is taken for the time period January 2000 to April 2014. When comparing the earthquakes in the whole time period the best is the earthquakes which are greater than four. The major earthquakes of magnitude greater than four which are considered in the analysis are occurred on the dates 26th December 2004, 28th March 2005, 12th September 2007 and 11th April 2012.

For the statistical analysis number of earthquakes occurred for a period of 24 months before and after a major is considered where some major earthquakes also falls into the considered 24 month period for certain earthquakes. The effect by them to the considered major earthquake is not taken into consideration in the analysis process. The earthquakes are considered to be independent of each other. When whole region is considered the aftershocks play main role in the analysis. In general aftershocks increase in greatly after an every major earthquake and they are more common near to the epicenter of main earthquakes and along the plate boundary. Therefore the earthquakes along the plate boundary are filtered.

The main two types of earthquakes are Dip slip and Strike slip. The earthquakes occurred on 26th December 2004, 28th March 2005 and 12th September 2007 are Dip slips while the one on 11th April 2012 is a strike slip one. The Dip slip type earthquakes do not creates stresses or strains in the plate but strike slip types does. Dip slips type mechanism does not accumulate a large amount of strain on plates therefore it does not affect the future number of earthquakes. Statistical analysis results also shows that there is no any significant change in the number of events after these major earthquakes. When the earthquakes of $M>4$ are considered the result is also same except for the one occurred on 26th December 2004. It shows an increase in the number of events. Due to the large magnitude it may have created large number of aftershocks all over the plate in large magnitudes.

Strike slips are the ones that creates large amount of strain on the plate increasing the number of earthquakes. The result of the analysis shows that the number of events has increased after the earthquake on 11th April 2012. This result agrees with the results obtained by Pollitze, et al. (2012) from a different method. They show that large number of earthquakes have been triggered worldwide after the M8.6 Strike Slip event that occurred in Sumatra region on $11^{\text {th }}$ April 2012. Due to this intra-oceanic earthquake seismicity has increased worldwide and it reached remote distances of 10,000-20,000 km from the main shock, much wider than the nearfield aftershock zone surrounding a large main shock. In addition to the $2012 \mathrm{M}=8.6$ event, seismicity has increased in the elevated strain region within 10 days after the 1977 M8.3 Indian Ocean earthquake (Johnson, et al., 2015). Further, the $2002 \mathrm{M}_{\mathrm{w}} 7.9$ Denali Fault, the $2004 \mathrm{M}_{\mathrm{w}}$ 9.2 Sumatra, the $2010 \mathrm{M}_{\mathrm{w}} 8.8$ Maule, Chile earthquake and the $2011 \mathrm{M}_{\mathrm{w}} 9.1$ Tohoku-Oki have triggered clear tremors in various regions by distant earthquakes (Richards-Dinger et al., 2010 Aiken et al., 2013; Chao et al., 2013;). Therefore it is clear that seismic activity is triggered after the occurrence of a large earthquake. However in $2012 \mathrm{M}=8.6$ event is a special event and due to its strike slip mechanism property the earthquake activity even large distances.

Further, when analysis of earthquake energy released before and after the major earthquakes taken into the consideration it shows no increase of energy released after the major events of 2004, 2005, 2007. But there is a clear rise of energy released after the major event of 
2012 April $M=8.6$. Thus, it confirms the statistical analysis results that the earthquake activity has increased after 2012 major earthquake.

\section{Conclusions}

The objective of the research was to find whether there is any change in the number of events due to the major events in the region. There were four major events happened in the region from 2000 to 2014. For this purpose both qualitative and quantitative analysis were carried out. The quantitative analysis was done using a statistical technique name Mann Whitney U test, a non-parametric method. In addition Energy released before and after the major events were used to further assist the statistical analysis.

The number of events has not changed after the occurrence of 26th December 2004, 28th March 2005, and 12th September 2007 events. The number of earthquakes of M>4 has increased after the occurrence of earthquake of 11th April 2012 which is also confirmed by the analysis of earthquake energy released before and after the major events as it indicates no increase of released energy after the events of 2004, 2005, 2007 whereas the total earthquake energy after the $2012 \mathrm{M}=8.6$ event has increased significantly.

When considered the increase of earthquakes in the context of Sri Lanka, recent earthquake activity of Sri Lanka has increased specially in Central part and Eastern part of Sri Lanka near Maduruoya, Highland-Wijayan boundary and Wadinagala area of Ampara District. The increase of earthquakes in central area may be due to the activation of old faults due to the occurrence of 2012 M8.6 strike-slip earthquake or else due to the effects of large reservoirs which cause large amount of stress to build up in the rock layer underneath due to the weight of the high amount of water. Further, the rise in earthquakes in the Eastern region, especially in Eastern part of Sri Lanka near Maduruoya, Highland-Wijayan boundary and Wadinagala area of Ampara District could be the stress change of the region due to the occurrence of 2012 M8.6 strike-slip earthquake (Gamage, 2015).

\section{Acknowledgement}

We thank the IRIS DMC for achieving and distributing the seismic data.

\section{References}

Aiken C.Z., Peng., Chao K. 2013. Tremors along the Queen Charlotte Margin triggered by large teleseismic earthquakes, Geophysics Research Letters, 40: 829-834.

California Institute of Technology Tectonics Observatory. Why Earthquakes and Tsunamis occur in the Sumatra region. [Online] Available from: http://www.tectonics. caltech.edu/outreach/highlights/sumatra/why.html

Chao K., Peng Z., Gonzalez-Huizar H., Aiken C., Enescu B., Kao H., Velasco A.A., Obara K., Matsuzawa T. 2013. A global search for triggered tremor following the $2011 \mathrm{Mw} 9.0$ Tohoku Earthquake. Bulletin of the Seismological Society of America, 103(2B): 15511571.

De Mets C., Gordon R., Argus D. 2010. Geologically current plate motions. Geophysical Journal International, 181(1), 1-80.

Earthquakes Available at: http://www.math.wichita.edu/ richardson/earthquake.html

Explorable. 2009 Mann-Whitney U-Test. [Online] Available from: https://explorable.com/ Mann-Whitney-u-test 
Findlay D. 2002. Plate tectonics and this expanding earth [Online] Available from: http://users.indigo.net.au/don/index.html

Gamage S.S.N. 2015. Role of seismology in risk assessment and mitigation of earthquakes and Tsunamis in Sri Lanka, $71^{\text {st }}$ Annual session of the Sri Lanka Association for the Advancement of Science, December, 2015, Colombo, Sri Lanka. Proceedings of the 71th Annual Sessions, 29-41.

Gamage S.S.N. 2017. Seismic activity near the Sunda and Andaman Trenches in the Sumatra subduction zone. International Journal of multidisciplinary Studies, 4(2): 49-54.

Gamage S.S.N., Umino N., Hasegawa A., Kirby S. 2009. Offshore double-planed shallow seismic zone in the NE Japan forearc region revealed by $\mathrm{sP}$ depth phases recorded by regional networks, Geophysical Journal International, 178: 195-214.

Johnson C.W. Burgmann R., Pollitz F.F. 2015. Rare dynamic triggering of remote $\mathrm{M} \geq 5.5$ earthquakes from global catalog analysis. Journal of Geophysical Research: Solid Earth, 120: 1748-1761.

Laerd Statistics. Mann-Whitney U-Test using Minitab. [Online] available from: https://statistics.laerd.com/minitab-tutorials/mann-whitney-u-test-using-minitab.php.

Mood A.M., Graybill F.A., Boes D.C. 2010. Introduction to the theory of statistics. $3^{\text {rd }}$ edition. Tata McGraw Hill, New Delhi, India.

Nelson S.A. 2012. Physical Geology. [online] Continental drift, Sea floor spreading, and plate tectonics. Available from: www.tulane.edu/ sanelson/eens1110/pltect.pdf.

Pollitz F.F., Stein R.S., Sevilgen V., Bürgmann R. 2012. The 11 April 2012 east Indian Ocean earthquake triggered large aftershocks worldwide. Nature, 490 (7419): 250-253.

Read H.H., Watson J. 1975. Introduction to geology. Halsted, New York.

Richards-Dinger K., Stein R.S., Toda S. 2010. Decay of aftershock density with distance does not indicate triggering by dynamic stress, Nature, 467(7315): 583-586.

Sanders R. 2012. Large 2012 earthquake triggered temblors worldwide for nearly a week. US Berkely News center [Online] $26^{\text {th }}$ September. Available from: http://newscenter. berkeley.edu/ 2012/09/26/large-2012-earthquake-triggered-temblors-worldwide-fornearly-a-week/

Shedlock M.K., Pakiser L.C. 1995. Earthquakes. [Online] Available from: http://pubs.usgs.gov/ gip/earthq1/index.html.

USGS. 2013 Earthquakes and plate tectonics. [Online] Available from: http://earthquake. usgs.gov/learn/topics/plate_tectonics/rift_man.php. 